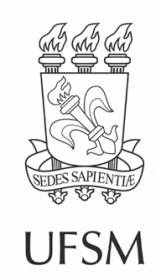

\title{
Artigos
}

\section{Análise e distribuição espacial do ruído no posto de trabalho do operador e nas proximidades de máquinas agrícolas e florestais}

\author{
Analysis of spatial distribution of noise near agricultural and forestry \\ machinery
}

\author{
Ricardo Kozoroski Veiga $1 \bullet$, Leila Amaral Gontijo " ๑, \\ Fabrício Campos Masiero ${ }^{1}{ }^{\oplus}$, Juclei Venturi ${ }^{1 \oplus}$ \\ I Instituto Federal Catarinense, Rio do Sul, SC, Brasil \\ " Universidade Federal de Santa Catarina, Florianópolis, SC, Brasil
}

\section{RESUMO}

Um dos principais riscos ergonômicos ao qual são submetidos os operadores de máquinas agrícolas e florestais é o ruído. Porém, a intensidade de ruído experimentada por profissionais que atuam, tanto como operadores como auxiliares nas imediações dessas máquinas, é pouco conhecida. Por isso, esta pesquisa objetivou quantificar os níveis de ruídos sofridos por trabalhadores nas proximidades das frentes de trabalho agrícola e florestal. Para isso, foram utilizadas neste trabalho as seguintes máquinas: Trator da marca New Holland modelo TM 135-4×2 com tração dianteira auxiliar (TDA); trator da marca Valmet, modelo 785 4×2; trator da marca Jonh Deere, modelo 5065E-TDA; motocultivador da marca Kubota M 160 e motosserra da marca Husqvarna modelo 281 XP. Os dados foram coletados em rotação nominal de trabalho de cada máquina. As avaliações de ruídos foram realizadas com medidor de pressão sonora (decibelímetro) no entorno de cada máquina posicionada no centro de uma área plana, com as dimensões de $9 \times 9$ metros, totalizando 100 pontos, utilizando-se os dados coletados para a geração de mapas de ruído, utilizando o programa Surfer ${ }^{\circledR 8.0 . ~ O s ~ d a d o s ~ f o r a m ~ a v a l i a d o s ~ p e l a ~ a n a ́ l i s e ~}$ de variância utilizando o teste ta $5 \%$ de significância, utilizado o coeficiente de Pearsonnas correlações. O ruído no entorno da máquina pode ser maior que no próprio posto de trabalho do operador, sendo que as distâncias seguras para uma jornada de 8 horas variaram entre 3 a 6,5 metros para tratores e 4,7 metros para a motosserra. Ao avaliar o ruído no posto de trabalho das máquinas, com exceção do trator com cabine, faz-se necessária a utilização de protetor auricular para uma jornada superior a 3 horas sendo que para a motosserra o tempo máximo de exposição foi de 1 hora.

Palavras-chave: Mapas; Ergonomia; Posto de trabalho 


\section{ABSTRACT}

One of the main ergonomic risks to which operators of agricultural and forestry machines are subjected is noise. However, the noise intensity experienced by professionals who work, both as operators and assistants in the vicinity of these machines is little known. This study aimed to quantify the noise levels experienced by operators and other workers in the vicinity of fronts of agricultural and forestry work. The following machines were evaluated: New Holland Tractor model TM-135 TDA, Valmet tractor, model 785 4x2, John Deere tractor, model 5065E TDA, Kubota power tiller and Husqvarna chainsaws model 281XP. Data were collected at nominal operating rotation of each machine. The noise assessments were performed with a measuring sound pressure (decibel) placed around each machine positioned in the center of a flat area, with dimensions of $9 \times 9$ meters, totaling 100 points. To generate noise maps, the program Surfer $\circledast 8.0$ was used. The data were treated, when significant at $5 \%$ probability, and t-test analysis of variance, the Pearson correlation coefficient was used. The results showed that the noise around the machine can be greater than at the workstation. The safe distances for an 8-hour workday ranged from 3 to 6.5 meters for tractors and 4.7 meters to the chainsaw. Except for the machine A, for all the others, it is necessary to use ear plugs for more than 3 hours of work. To the chainsaw, the maximum exposure time is 1 hour. The Surfer $8^{8} .0$ program was presented as an efficient tool for the construction of noise maps.

Keywords: Maps; Ergonomics; Workstation

\section{INTRODUÇÃO}

A crescente aplicação de processos mecanizados na agricultura e na atividade florestal trouxe vários benefícios de ordem econômica para esses setores, tais como a redução de tempos de processos produtivos e a diminuição dos custos com mão de obra. Grande parte das máquinas utilizadas nesses setores é motorizada e utiliza motores de combustão interna do ciclo Otto ou Diesel. Os projetos dessas máquinas nem sempre atentam para fatores humanos e sua utilização por longos períodos pode provocar impacto negativo na saúde de seus operadores. As principais deficiências dessas máquinas são de ordem ergonômica. Essas limitações ergonômicas podem, direta ou indiretamente, colaborar para o aumento dos acidentes de trabalho. Dentre os principais problemas das máquinas motorizadas está a exposição do operador ao ruído que, segundo Cunha et al. (2009), pode causar sensação de desconforto e gradual perda da sensibilidade auditiva. A velocidade dessa perda é determinada pela intensidade, frequência e tempo de exposição ao ruído. 
Segundo Machado (2014), a motosserra é uma máquina portátil utilizada na colheita florestal semimecanizada e está presente nas etapas de derrubada, desgalhamento e processamento da madeira. Essa máquina exige o uso de protetor auricular devido ao elevado ruído gerado.Para Sant'Anna (1999) o corte com motosserra permite produtividade individual relativamente elevada com baixo investimento inicial. Como desvantagem está o fato de ser uma máquina perigosa e entre os riscos inerentes à sua operação está o ruído. Segundo Sant'Anna et al. (1995), é importante que as empresas florestais adquiram motosserras profissionais, de baixo peso, design ergonômico, baixo nível de ruído e de vibração.

Além das máquinas especializadas, como o Feller-buncher, Harvester e o Fellerskidder, os sistemas agroflorestais empregam os tratores agrícolas na extração de madeira. A fase do processo produtivo florestal que mais sofreu alteração devido à introdução de tratores foi a extração da madeira. Segundo Machado (2014), na operação de extração podem ser utilizados tratores agrícolas adaptados, seja com caçambas ou com guinchos. Para o autor os aspectos importantes a serem observados em avaliações ergonômicas de máquinas desta natureza são a vibração e o ruído no posto do operador. Durante a realização desses trabalhos, os operadores ficam expostos às condições climáticas adversas (temperatura, poeira, umidade) e condições impostas pela máquina (ruídos, vibrações, postura, gases, temperatura), sendo as últimas decorrentes da concepção e do projeto do trator. Mesmo nos dias atuais, máquinas são comercializadas sem uma preocupação aparente com relação a parâmetros indispensáveis para a realização de determinado trabalho com conforto e segurança (LIMA et al., 2005). Schlosser e Debiasi (2002) concluíram que nos tratores não cabinados, os níveis de ruído ficaram acima do limite considerado salubre. Com relação às imediações do posto de trabalho do trator, os níveis de ruído mostraram-se fora da norma (para trabalhadores sem proteção) no lado do escapamento do trator até quatro metros de distância, demonstrando que também é importante o cuidado das pessoas que trabalham próximas às máquinas (CUNHA; DUARTE; RODRIGUES, 2009). 
Níveis elevados de ruído podem produzir perda permanente da capacidade auditiva, bem como efeitos psicofisiológicos negativos, inclusive aumentando o risco de acidentes, como citam Wictor \& Bazzanella (2012). Para Carvalho (2009), uma das principais fontes causadoras de estresse nos trabalhadores é o ruído, sendo que a intensidade e o tempo de exposição a esse fator afetam seu desempenho no trabalho. Segundo Simone et al. (2006), a permanência em locais de trabalho que apresentam níveis de ruído de 85 a 90 decibéis ( $\mathrm{dB}(\mathrm{A})$ ) oferece grande risco de surdez, o qual aumenta em função da frequência dos ruídos e do tempo de permanência nessa situação. As alterações ocasionadas pelos altos níveis de potência sonora não resultam em efeitos imediatos, mas cumulativos, e vão se estabelecendo com o tempo (NORONHA et al. 2005).

Devido à relação entre a exposição ao risco e à saúde do trabalhador, a legislação brasileira especifica um período máximo de exposição permitido. De acordo com a Norma Regulamentadora N¹5, os níveis de ruído contínuo ou intermitente devem ser medidos em decibéis ( $\mathrm{dB}$ ), com a utilização de um instrumento de nível de pressão sonora (decibelímetro) onde as leituras devem ser feitas próximo ao ouvido do operador. A norma preconiza que para a intensidade de $85 \mathrm{~dB}(\mathrm{~A})$ a exposição salubre é de 8 horas diárias e para $115 \mathrm{~dB}(\mathrm{~A})$ é de apenas 7 minutos, não sendo permitido a exposição a níveis de ruído acima desse limite para operadores que não utilizam equipamentos de proteção, podendo proporcionar risco grave aos mesmos (SEGURANÇA..., 2011).

Ainda pouco utilizado nas avaliações das atividades agrícolas e florestais, o instrumento demedição de ruídos(decibelímetro)pode servirpara alertar trabalhadores quanto a níveis críticos de exposição ao ruído. Seu uso deve ser sistemático, uma vez que as condições climáticas, espaciais e estado de conservação das máquinas interfere na emissão e propagação do ruído. O desgaste natural de componentes de máquinas motorizadas, como escapamento, lataria e transmissão, contribui para o aumento do nível de ruído, potencializando o risco à saúde do operador (VENTURI et al. 2014). Além 
dos operadores, os trabalhadores que executam atividades no entorno da máquina em funcionamento estão sujeitos a intensidades potencialmente perigosas, mesmo a metros de distância do seu ápice (VEIGA, et al. 2014).

O ruído, por ser uma onda mecânica, tem sua propagação em todas as direções, tridimensionalmente. Assim para a determinação das intensidades sonoras distribuídas nas proximidades das máquinas exige-se método complexo de mensuração. Também sua representação gráfica exige modernos recursos que possibilitam a criação de modelos da distribuição espacial do ruído. Esses modelos são chamados mapas. Conhecendo os valores de ruído apresentados nos mapas, tem-se uma noção do risco que estão sujeitos os trabalhadores nas proximidades das máquinas utilizadas nos processos agrícolas e florestais. Programas computacionais para mapeamento de áreas cultivadas vêm sendo utilizados na agricultura de precisão, ramo moderno que lança mão de tecnologias que permitem visualização de pontos críticos, identificados por coordenadas espaciais e com grande acuracidade.Yanagi Júnior et al. (2012), avaliando a variabilidade espacial do ruído de um trator agrícola em diferentes direções, concluíram que os níveis de ruído estavam acima de 85 dB(A) próximo ao operador, e que os mapas gerados por programas de geoestatística podem ser utilizados para definir áreas com diferentes níveis de ruído em torno do trator. Iniciativas da aplicação, com bons resultados, do programa Surfer® nas ciências naturais são vistas em Biesterveld et al. (2004), na construção de mapas de contaminação do solo, Roque et al. (2008), na confecção de mapas de produtividade do feijoeiro e em Oliveira et al. (2009), no mapeamento da produção de laranjeiras georreferenciadas.O programa Surfer ${ }^{\circledR}$, produzido pela Golden Software, possibilita a visualização de contornos em três dimensões, além de um pacote para modelagem de superfície. É amplamente utilizado para modelagem de terreno, visualização da paisagem, análise de superfícies, mapeamento de contorno, geração de mapas de superfície, volumetria entre outras aplicações (SOFTWARE..., 2014). Em estudos ergonômicos, especificamente para o mapeamento de ruído em máquinas na área 
rural, a aplicação de softwares é recente e busca a visualização dos pontos críticos de ruídos não somente no posto de trabalho do operador, mas também nas imediações das máquinas em funcionamento.

Dessa maneira, este estudo teve como objetivo construir, com auxílio do software Surfer ${ }^{\circledR}$, mapas de ruído em torno de máquinas utilizadas na agricultura e na atividade florestal e comparar esses valores aos especificados em norma, a fim de determinar distâncias de afastamentos seguras para trabalhadores nas imediações dessas máquinas.

\section{MATERIAIS E MÉTODOS}

O trabalho foi conduzido no Laboratório de Mecanização Agrícola do Instituto Federal Catarinense - IFC, Campus Rio do Sul (SC), Brasil, localizado a latitude 31 52’00" Sul e longitude 52²1'24" e com a altitude de 697 metros, referente ao ponto central da Instituição.

Para a realização do trabalho foram utilizadas as máquinas descritas na Tabela 1:

Tabela 1 - Caracterização das máquinas empregadas no estudo

\begin{tabular}{lccccc}
\hline Máquina & Tipo & Marca & Modelo/Ano & $\begin{array}{c}\text { Potência } \\
(\mathbf{k W})^{\mathbf{2}}\end{array}$ & $\begin{array}{c}\text { Rotação } \\
(\text { (RPM) }\end{array}$ \\
\hline A & Trator & New Holland & TM 135-TDA 1,2009 & 102.07 & 2200 \\
B & Trator & Valmet & $7854 \times 2,1995$ & 55.88 & 2400 \\
C & Trator & John Deere & 5065E-TDA 1,2010 & 48.43 & 1500 \\
D & Motocultivador & Kubota & M 160, 1995 & 11.92 & 2200 \\
E & Motosserra & Husqvarna & 288 XP, 2011 & 4.30 & 9300 \\
\hline
\end{tabular}

Fonte: Autores (2014)

Em que: ${ }^{1}$ tração dianteira auxiliar; ${ }^{2}$ quilowatt, ${ }^{3}$ rotações por minuto.

A escolha das máquinas seguiu o critério da representatividade na economia rural da região do Alto Vale do Itajaí, SC, onde predomina a agricultura familiar e o sistema agroflorestal, com auxílio detratores, motocultivadores e motosserras. Os níveis de ruídos contínuos foram determinados utilizando-se um decibelímetro digital da marca ICEL modelo DL-4020, calibrado pelo instrumento da marca Hikari, modelo HCD-90 de acordo com a 
norma IEC 60942, classe 2. Foi utilizado protetor de vento e a escala foi o decibel (dB).O instrumento foi ajustado ao nível de pressão sonora operando no circuito de compensação "A" e circuito de resposta lenta (SLOW), de acordo com a NR-15 (SEGURANÇA..., 2011).

As coletas seguiram as orientações do Código 5 da Organização para a Cooperação e Desenvolvimento Econômico [OCDE] (2012), tendo sido realizadas as medições em dia de tempo bom, com pouco vento, com o ruído ambiente e de vento mensurados, com distância mínima até obstáculos superior a 20 metros. Ruídos estranhos que ocorreram durante a leitura e que não estavam ligados à medição de nível de som foram desconsiderados. No dia do experimento a velocidade do vento e temperatura eram respectivamente de $19,5^{\circ} \mathrm{Ce}$ 1,7 m.s $\mathrm{s}^{-1} \mathrm{com}$ direção nordeste, dados observados por meio de uma estação meteorológica pertencente ao Campus e instalada nas proximidades do local do experimento.

Para a avaliação dos níveis de ruídos, posicionou-se cada máquina no centro de uma área delimitada para as medições, com as dimensões de 9 × 9 metros com pontos demarcados com estacas de madeira, totalizando 100 pontos, conforme representado na Figura 1.

Figura 1 - Distribuição de pontos de coleta de ruídos na área demarcada

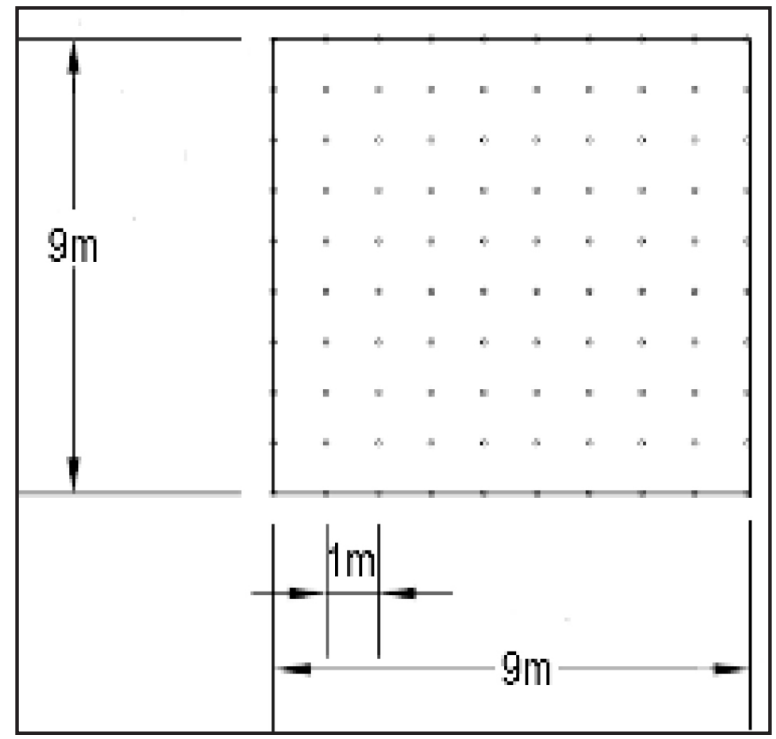

Fonte: Autores (2014) 
O captador acústico do decibelímetro foi posicionado a altura do ouvido de uma pessoa de estatura mediana (165,0 centímetros), seguindo como referência medidas antropométricas sugeridas por lida (2005). Para manter a altura das medições, utilizouse uma haste de aço, como apoio do instrumento. Para cada ponto foram realizadas três repetições. Nos pontos de máxima intensidade, repetiu-se a coleta, totalizando seis repetições. A medição no posto do operador realizou-se com este na posição sentado, no caso dos tratores e motocultivador e operador em pé ao lado da máquina, no caso da motosserra. $O$ decibelímetro foi posicionado a 20 centímetros do ouvido e para cada posto de trabalho foram realizadas seis repetições.

Para a centralização das máquinas adotou-se o seguinte critério:

a) tratores: o centro geométrico da máquina foi considerado como o cruzamento das duas diagonais entre as rodas dianteiras e traseiras.

b) motosserra:o bloco do motor foi posicionado no centro geométrico da área.

c) motocultivador: centro do eixo dianteiro sobre o centro geométrico da área.

As Figuras 2 e 3 exemplificam o procedimento para trator e motosserra respectivamente.

Figura 2 - Demonstração da posição do trator para a coleta de dados

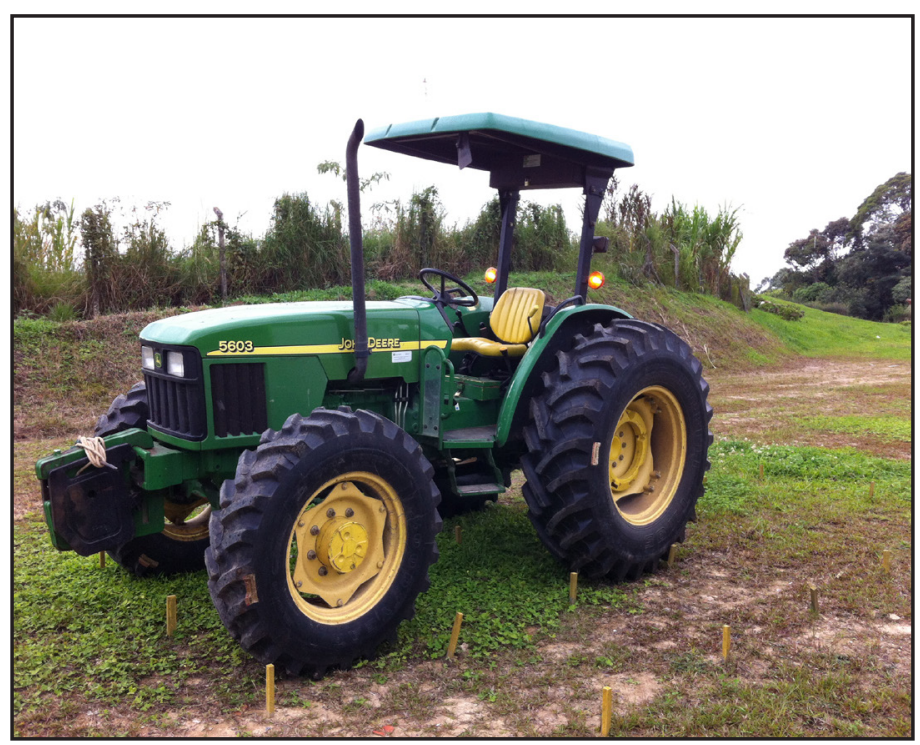

Fonte: Autores (2014) 
A rotação do motor utilizada para coleta de ruído seguiu a indicação de cada fabricante (apresentada no manual de operação), variando de 1.500 a 9.300 rotações por minuto.

Os dados obtidos foram digitados em planilha eletrônica e para cada ponto foi extraída a média das três repetições. Em seguida os dados tratados foram submetidos ao programa Surfer ${ }^{\circledR} 8.0$ para geração de mapas em duas e três dimensões (2D e 3D).

Figura 3 - Demonstração da posição da motosserra para coleta de dados

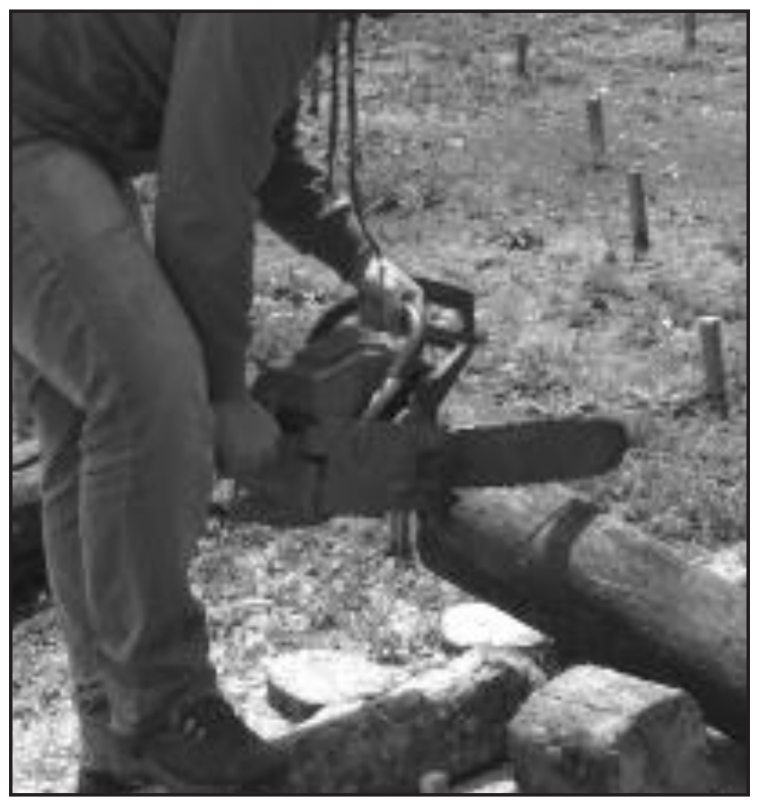

Fonte: Autores (2014)

Buscando conhecer a relação entre as variáveis potência, ruído, distância e RPM foi calculado, de forma pareada, o coeficiente de correlação de Pearson ( $r$ ) para 5 e 10\% de significância.

\section{RESULTADOS E DISCUSSÃO}

\subsection{Máquina A}

O mapa gerado no programa Surfer® 8.0 em 2D permite a visualização da distribuição do ruído espacialmente no plano do experimento. Demonstra baixo grau de simetria do ruído 
a partir da linha longitudinal da máquina. Também observou-se que o ponto de máximo ruído encontrava-se nas proximidades do escapamento da máquina, conforme Figura 4.

Figura 4 - Mapa 2D de distribuição do ruído para a máquina $\mathrm{A}$

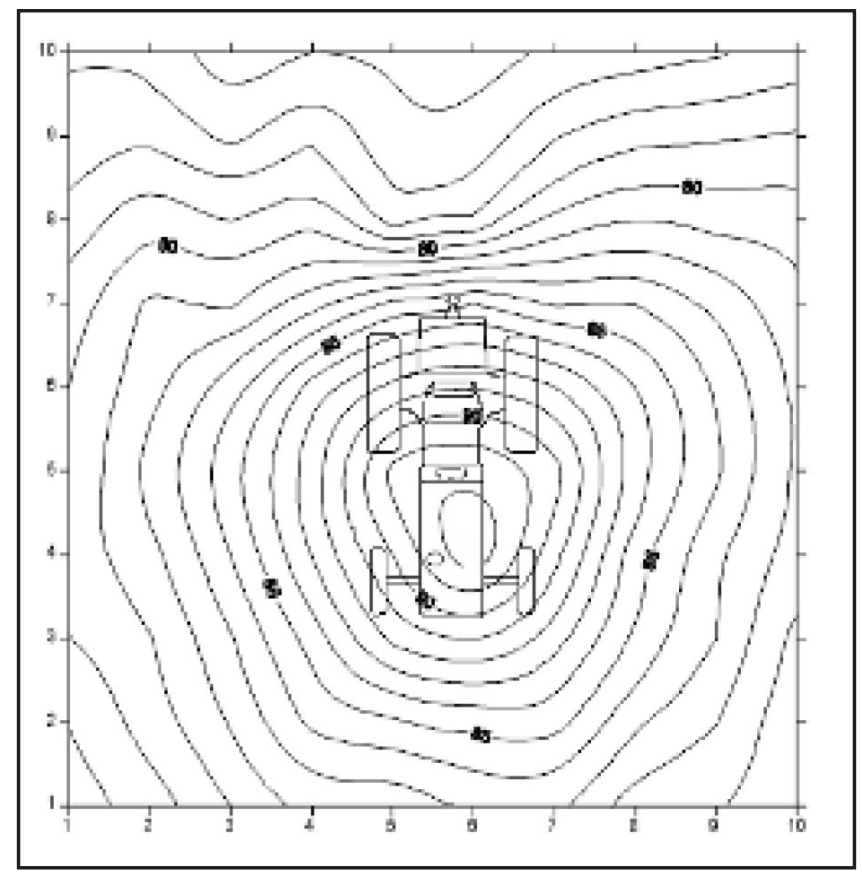

Fonte: Autores (2014)

$\mathrm{Na}$ Figura 5, o mapa 3D permite a visualização, por escala de cores, da intensidade sonora, além da localização espacial. Os pontos de máxima intensidade de ruído ocorreram nas proximidades do motor, onde registrou-se $92 \mathrm{~dB}(\mathrm{~A})$. No posto de trabalho, devido a atenuação provocada pela cabine, o operador experimenta $78,1 \mathrm{~dB}(\mathrm{~A})$. O mapa permite visualizar dois pontos próximos ao escapamento do trator que correspondem à lataria do mesmo e que vibram excitados pelo motor. Outra característica da distribuição é que o som é fortemente atenuado pelo rodado traseiro, comprimindo as linhas atrás do trator, em contraste com as linhas à frente deste. Considerando o nível máximo encontrado, a exposição diária permissível segundo a NR-15, sem a utilização de equipamento de proteção individual (EPI), seria de 3 horas. O operador, por estar sujeito a nível inferior à $85 \mathrm{~dB}(\mathrm{~A})$ não é obrigado, pela norma, a utilizar o protetor auricular. A distância segura para uma jornada de 8 horas nas proximidades da máquina foi avaliada geometricamente com base no gráfico $2 \mathrm{D}$ e corresponde a 3,2 metros. 
Figura 5 - Mapa 3D de distribuição de ruído para a máquina A

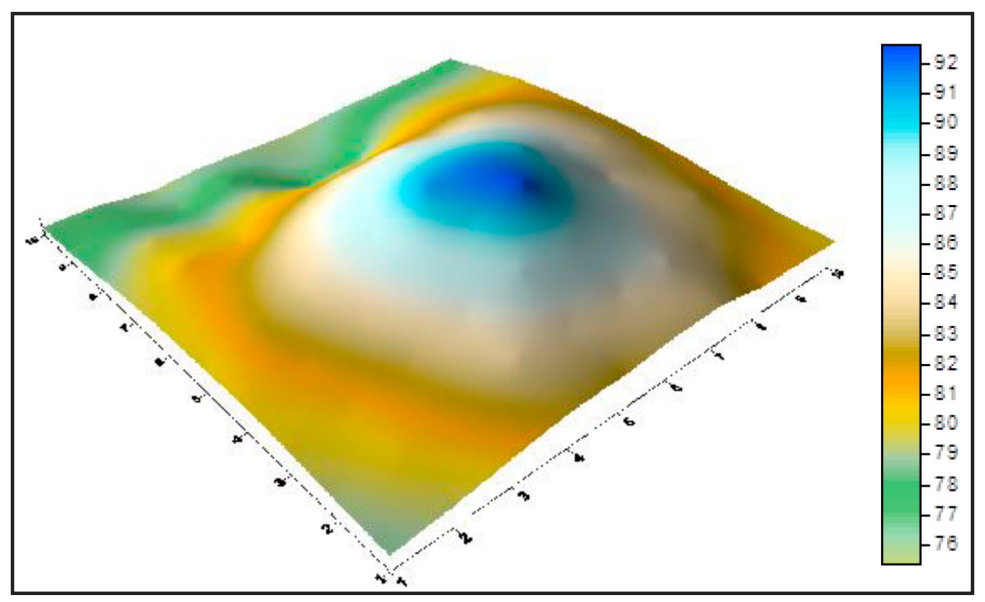

Fonte: Autores (2014)

\subsection{Máquina B}

O mapa em 2D permite a visualização da distribuição do ruído espacialmente e forte grau de concentricidade das linhas de ruído a partir do ponto de máxima intensidade. Evidenciou-se no posto do operador um nível de ruído de 94,2 dB(A), o que limita a utilização a 2(duas) horas e 15 minutos, sem o protetor auricular. O ponto de máximo ruído correu próximo ao escapamento da máquina, conforme Figura 6.

Figura 6 - Mapa 2D de distribuição do ruído para a máquina B

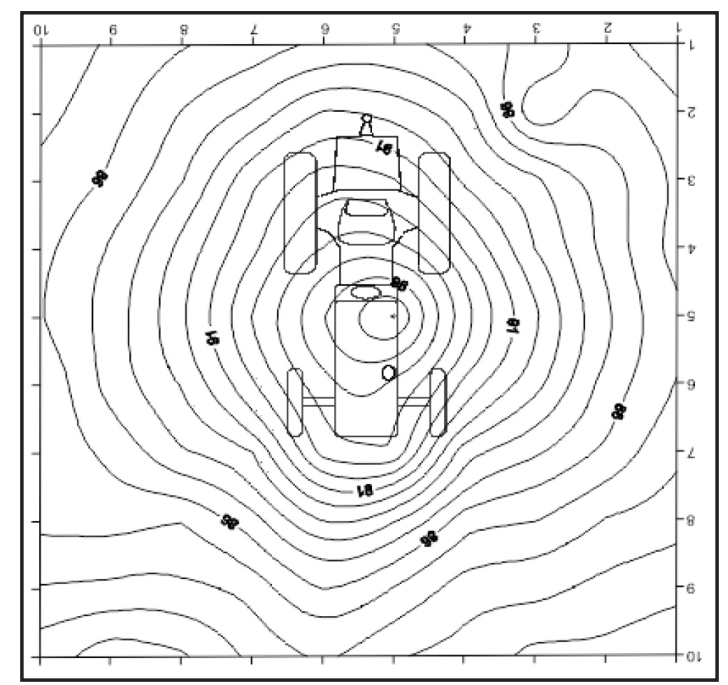

Fonte: Autores (2014) 
Assim como encontrado por Schlosser e Debiasi (2002), esta máquina, não cabinada, apresenta níveis de ruído acima do limite considerado salubre, no posto do operador.

Na Figura7, o mapa permite visualizar um ponto próximo ao escapamento do trator que corresponde à máxima intensidade sonora, no valor de 98,7dB(A), que localiza-se a aproximadamente um metro do escapamento, imediatamente acima do final do bloco do motor. A distribuição do som não demonstra ser atenuada pelos rodados, atingindo assim grandes distâncias.

Figura 7 - Mapa 3D de distribuição e intensidade de ruído para a máquina B

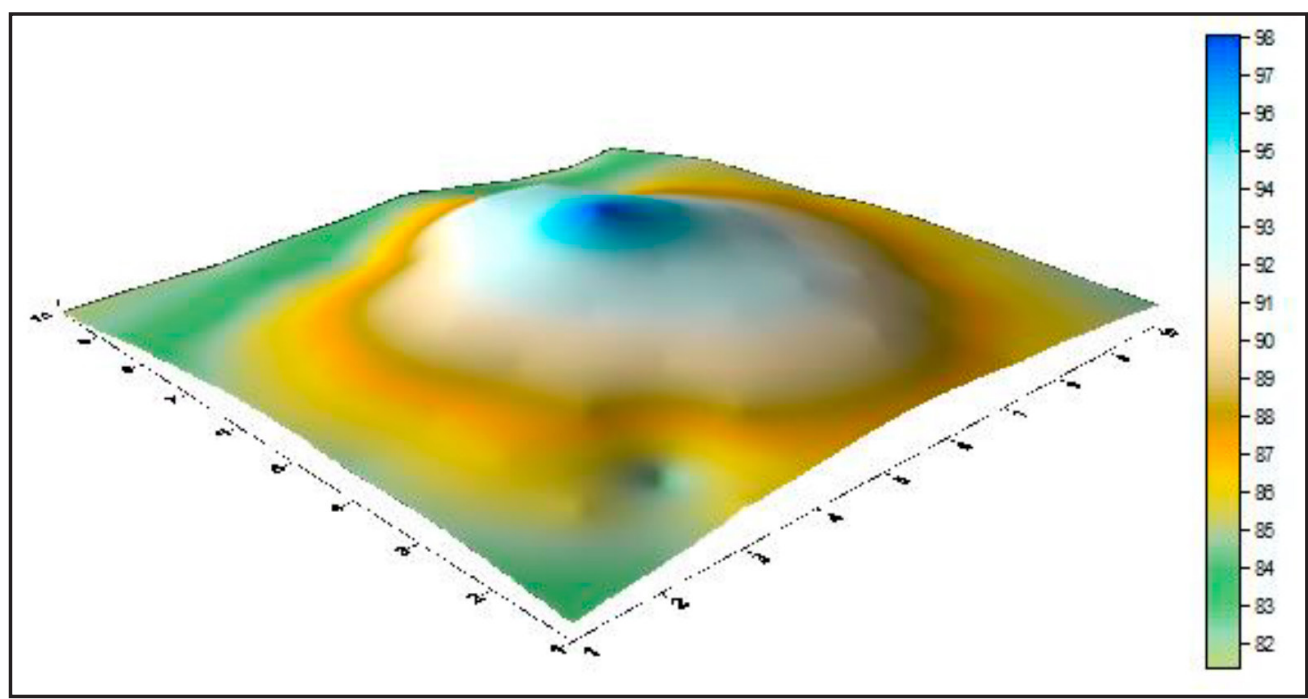

Fonte: Autores (2014)

Com o nível de ruído máximo de 98 dB(A), a exposição diária permissível, sem EPI, seria de 1(uma) hora e 15 minutos. A distância segura para uma jornada de 8 horas nas proximidades da máquina foi 6,5 metros.

\subsection{Máquina C}

A distribuição do ruído espacialmente demonstra forte atenuação pelo rodado traseiro e desvio das linhas para a esquerda da máquina. Evidenciou-se no posto do operador um nível de ruído de $89 \mathrm{~dB}(\mathrm{~A})$, o que limita a utilização a 4 horas e 30 minutos, sem o protetor auricular. O ponto de máximo ruído localizou-se próximo ao escapamento do veículo, conforme Figura 8. 
Analogamente ao que ocorre com a máquina $B$, concordando com o exposto por Schlosser , Debiasi (2002), os níveis de ruído ficaram acima do limite considerado salubre para o operador.

Figura 8 - Mapa 2D de distribuição do ruído para a máquina C

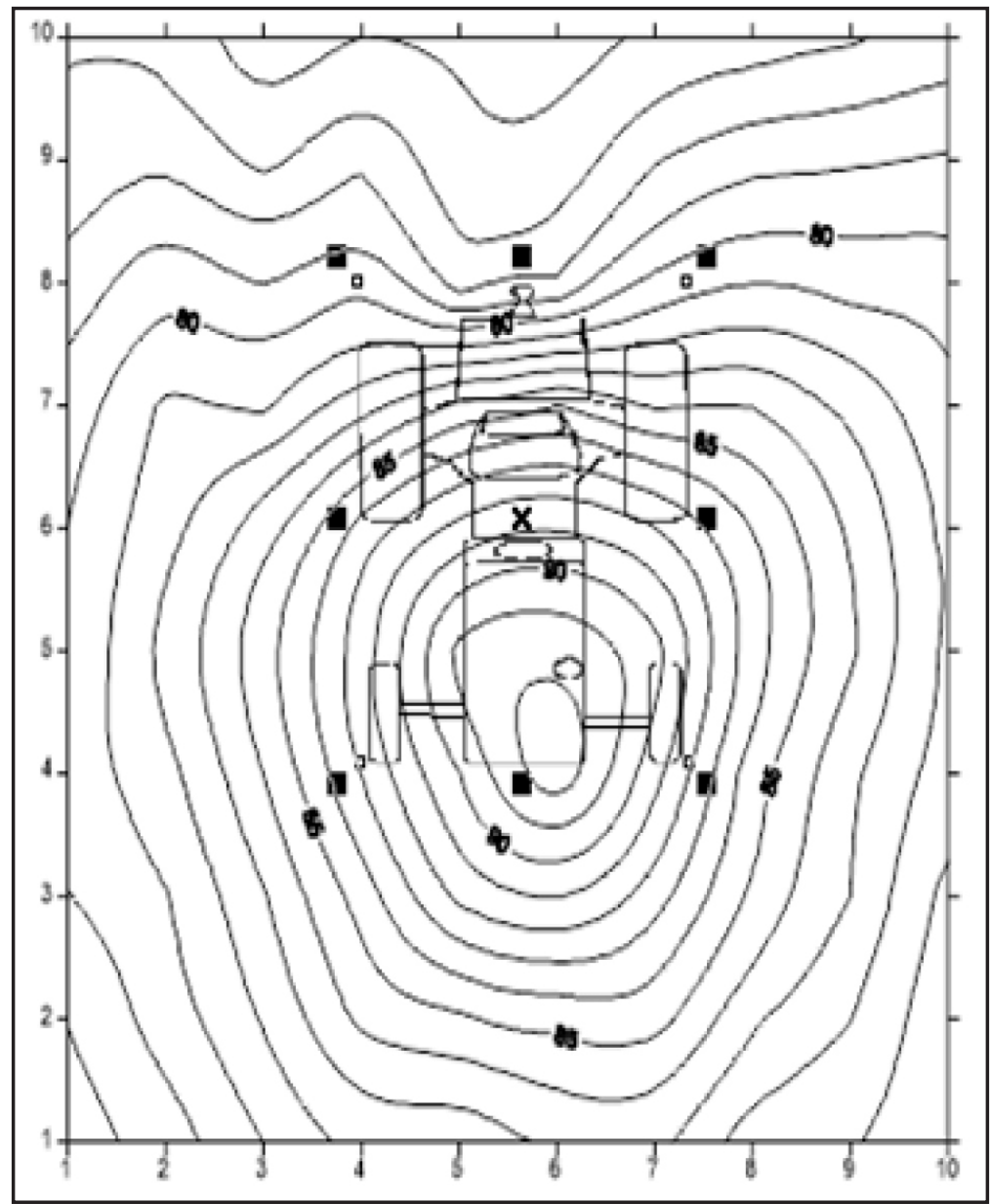

Fonte: Autores (2014)

A Figura9 permite a visualização dos pontos de máxima intensidade de ruído, que ocorreram nas proximidades do escapamento e à direita deste, sobre o capô da máquina, registrando-se $92 \mathrm{~dB}(\mathrm{~A})$. A intensidade sonora sofreu forte atenuação, reduzindo assim o impacto à saúde de trabalhadores nas imediações. Para um nível de ruído de 92 dB(A), a exposição diária permissível, sem EPI, é de 3 horas. A distância segura para uma jornada de 8 horas nas proximidades da máquina foi de 3 metros. 
Figura 9 - Mapa 3D de distribuição e intensidade de ruído para a máquina C

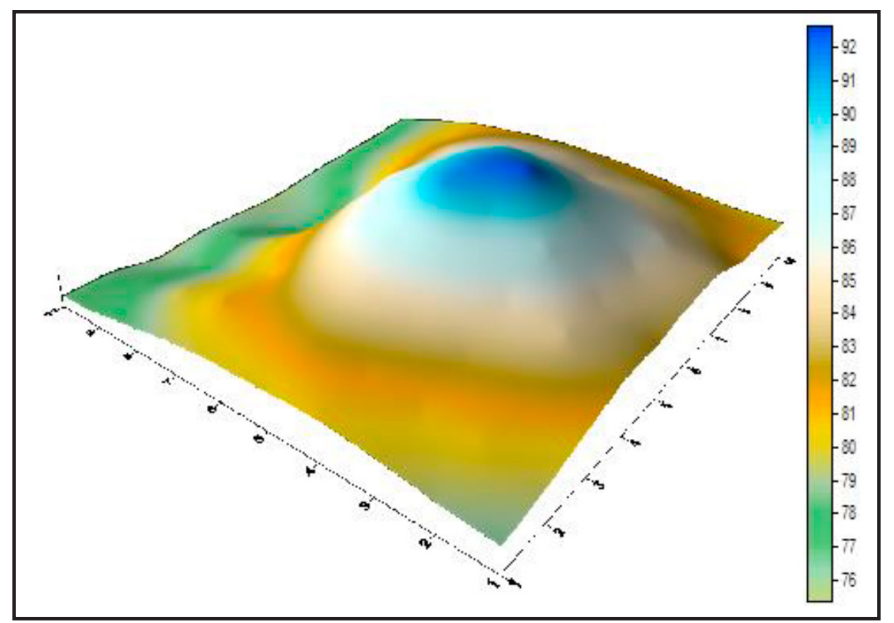

Fonte: Autores (2014)

\subsection{Máquina D}

A distribuição do ruído demonstra forte concentricidade a partir do ponto que corresponde ao escapamento da máquina. Ocorre leve atenuação devido à presença da carreta, acoplada à parte traseira da máquina, que forma uma barreira de aproximadamente 1,3 m de altura. Evidenciou-se no posto do operador um nível de ruído de $90 \mathrm{~dB}(\mathrm{~A})$, o que limita a utilização a 4 horas sem o protetor auricular. A representação da distribuição em 2D é apresentada na Figura10.

Figura 10 - Mapa 2D de distribuição do ruído para a máquina D

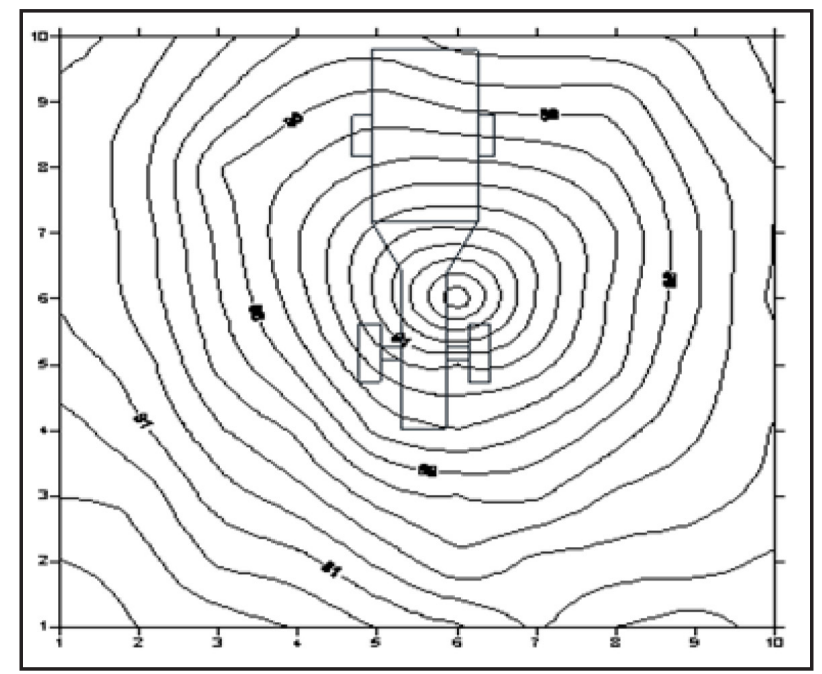

Fonte: Autores (2014) 
A Figura 11 permite visualizar um ponto isolado de máxima intensidade de ruído. A distribuição do som sofre maior atenuação na parte traseira em relação à dianteira e laterais. Com o nível de ruído de $95 \mathrm{~dB}(\mathrm{~A})$ a exposição diária permissível, sem EPI, seria de 2(duas) horas. A distância segura para uma jornada de 8 horas nas proximidades da máquina foi de 3,8 metros. Esse valor corrobora com Veiga et al. (2014), que alertam que trabalhadores que exercem atividades nas proximidades da máquina estão sujeitos a intensidades potencialmente perigosas, mesmo a metros de distância da fonte emissora. O agravante, nesse tipo de máquina, é sua utilização - mesmo sendo proibida por lei para o transporte de pessoas sobre a carreta, a aproximadamente 2 metros da fonte de máximo ruído.

Figura 11 - Mapa 3D de distribuição e intensidade de ruído para a máquina D

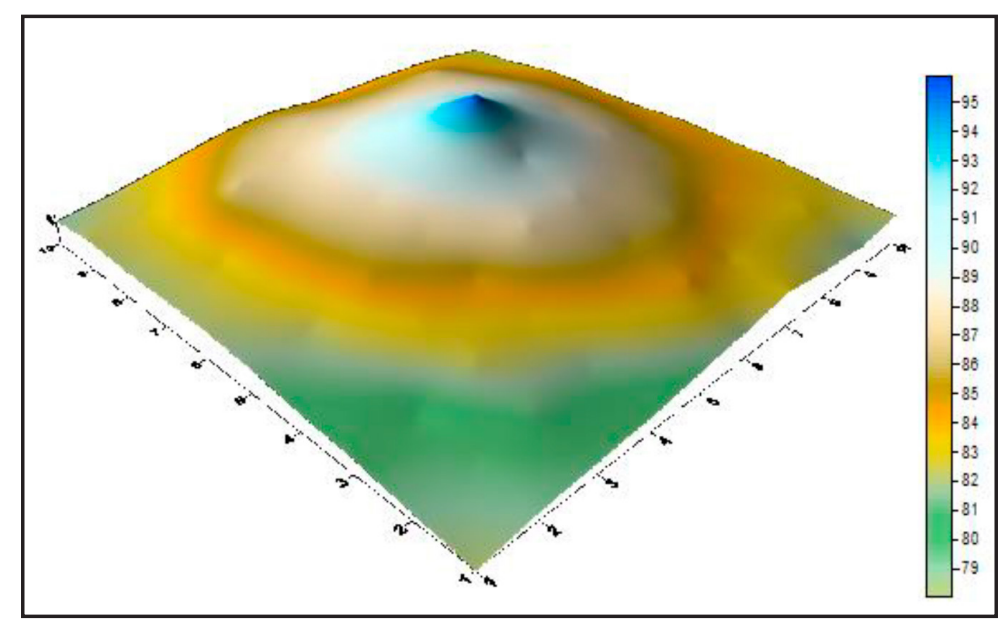

Fonte: Autores (2014)

\subsection{Máquina E}

A distribuiç̧ão do ruído demonstra simetria a partir da linha longitudinal da máquina, com ponto de máximo ruído na corrente de corte, acompanhado por picos correspondendo ao motor e escapamento da máquina. Neste caso, pelo ouvido do operador encontrar-se muito próximo ao motor da máquina, os valores de nível de ruído foram iguais. O posto do operador foi também o ponto de máximo ruído, atingindo um nível de aproximadamente 98dB(A), o que limita a utilização a 1(uma) hora sem o protetor auricular, conforme Figura 12. 
Figura 12 - Mapa 2D de distribuição do ruído para a máquina E

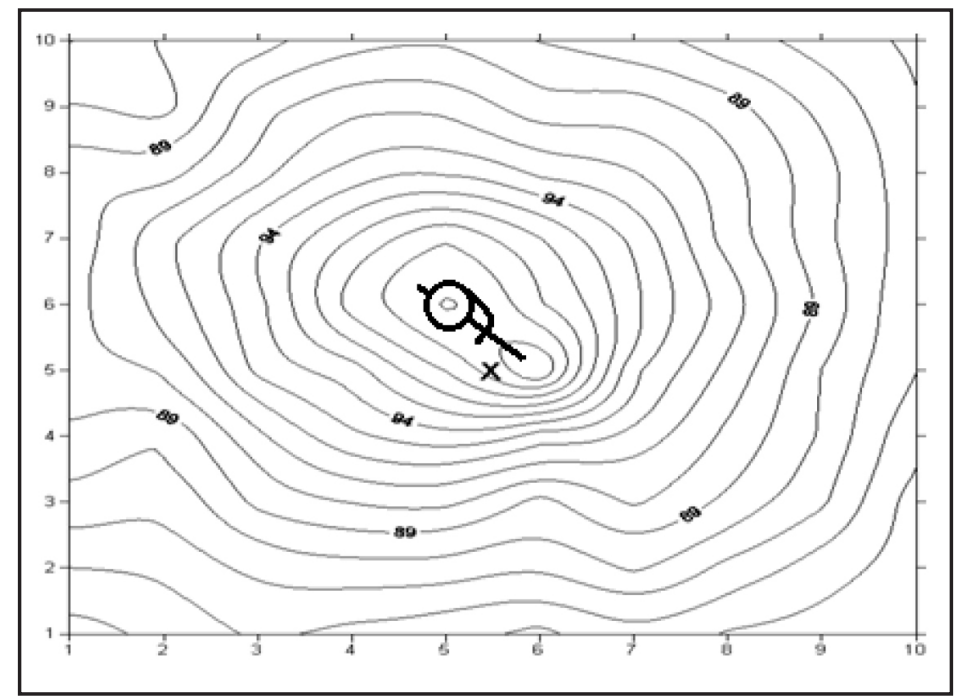

Fonte: Autores (2014)

Os valores encontrados corroboram tanto com Machado (2014) como com Sant'Anna (1999) quando afirmam que a motosserra apresenta como principal desvantagem o elevado nível de ruído. A Figura 13 apresenta o gráfico 3D, evidenciando o maior nível de ruído dentre as máquinas avaliadas. A distância segura foi de 4,7 metros.

Figura 13 - Mapa 3D de distribuição e intensidade de ruído para a máquina E

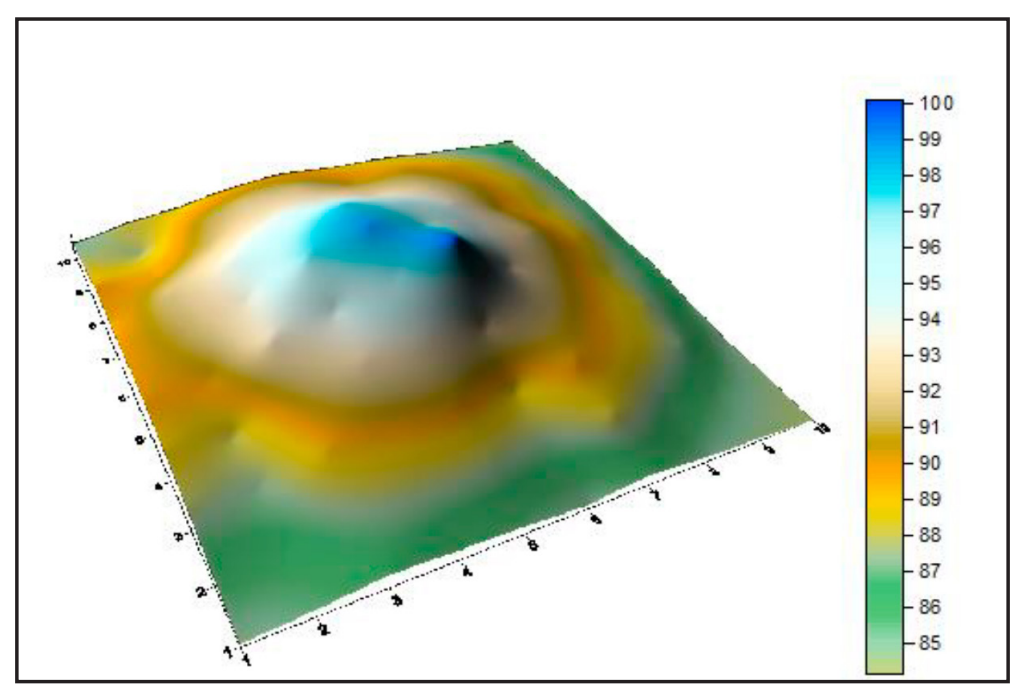

Fonte: Autores (2014) 


\subsection{Análise das máquinas}

Dentre os tratores avaliados, a marca B foi a que apresentou o maior nível de ruído na rotação de trabalho, 94,2 dB(A) no posto de trabalho e $98,7 \mathrm{~dB}(\mathrm{~A})$ em seu entorno. Entre os tratores foi o que necessitou maior afastamento para trabalhadores em solo: 6,5 metros. Já a motosserra (máquina E) apresentou maior risco à audição humana entre todas as máquinas, necessitando de um afastamento de 4,7 metros para que a pressão sonora se atenue para $85 \mathrm{~dB}(\mathrm{~A})$. Foi a que apresentou maior nível de ruído, tanto no posto de trabalho, como no ponto de máximo ruído, respectivamente 98,3 dB(A) e 98,7dBA. A máquina C apresentou menor distância de segurança: 3 metros.

As distâncias de segurança para cada máquina podem ser visualizadas na Figura 14.

Figura 14 - Distância de segurança para jornada de 8 horas sob nível de ruído de 85 $d B(A)$

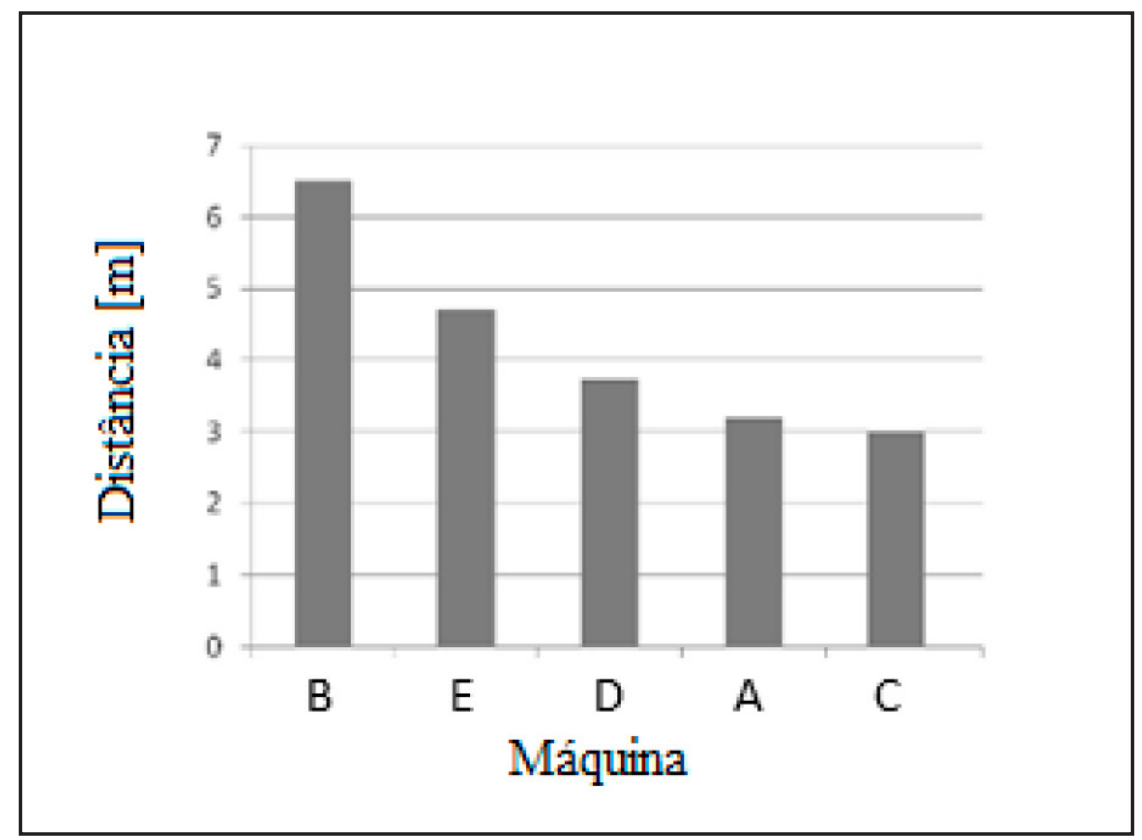

Fonte: Autores (2014)

Os valores de distância de segurança com seu respectivo nível de ruído máximo são apresentados na Figura 15.

Paralelamente ao estudo da propagação espacial do ruído e buscando 
aprofundamento no tema, foram investigadas possíveis correlações entre as variáveis ruído, potência, distância e rotações por minuto (RPM).

Figura 15 - Nível de ruído e distância de segurança para cada máquina

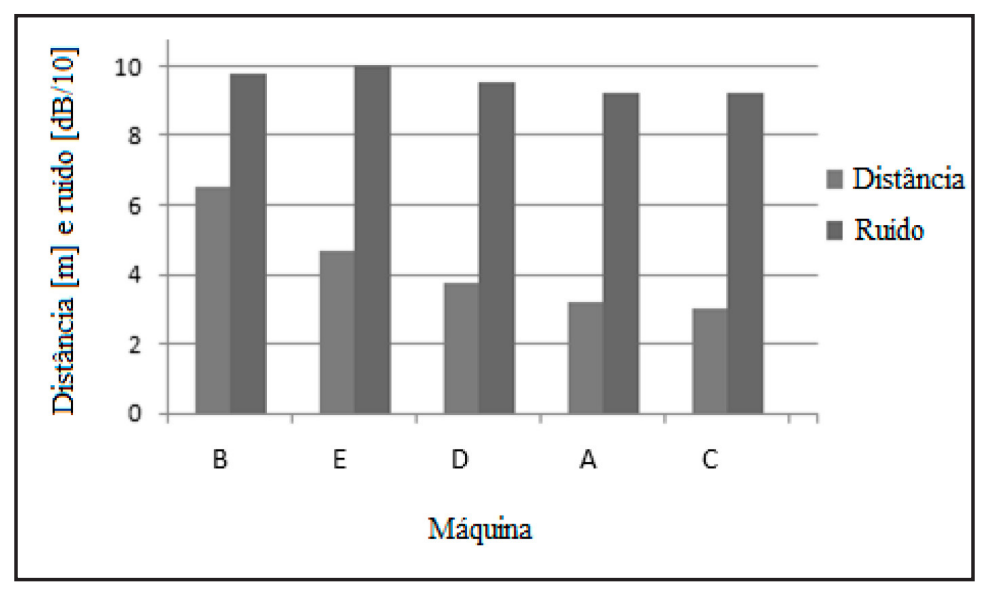

Fonte: Autores (2014)

Comprovou-se que existe uma correlação positiva forte entre o nível de ruído e a distância de segurança (Pearson = 0,891 a 5 e 10\% de significância) e uma correlação positiva forte entre o ruído e a RPM (Pearson = 0,754 a 10\% de significância).O resultado é expresso na Tabela2.

Tabela 2 - Correlações entre as variáveis ruído, potência, distância e RPM

\begin{tabular}{lcccc}
\hline \multirow{2}{*}{ Variáveis } & Pearson $(\mathbf{r})$ & Correlação & \multicolumn{2}{c}{ Significância, $\mathbf{a}$, num teste unilateral } \\
\cline { 4 - 5 } & & & $\mathbf{5 \%}(\mathbf{0 , 8 0 5})$ & $\mathbf{1 0 \%} \mathbf{( 0 , 6 8 7 )}$ \\
\hline RPM e Ruído & 0,764 & Positiva forte & Não Suficiente & Suficiente \\
RPM e Potência & $-0,561$ & Negativa Moderada & Não Suficiente & Não Suficiente \\
Potência e Ruído & $-0,627$ & Negativa Moderada & Não Suficiente & Não Suficiente \\
Ruído e Distância & 0,891 & Positiva forte & Suficiente & Suficiente \\
\hline
\end{tabular}

Fonte: Autores (2014)

Outra comparação foi entre o valor de ruído máximo emitido pela máquina e o encontrado no posto de trabalho. A diferença entre as duas condições indica o grau de atenuação do ruído em função de aspectos construtivos e/ou operacionais de cada máquina. 
A Figura 16 apresenta essa comparação. Observa-se que a máquina A possui maior atenuação, passando de 92,4 dB(A) (máximo) para 78,1 dB (A) no posto de trabalho. Já a máquina E apresenta a menor atenuação $(98,7$ para 98,3 dB(A)).

Figura 16 - Médias de ruído no posto de trabalho e a máxima encontrada em cada máquina

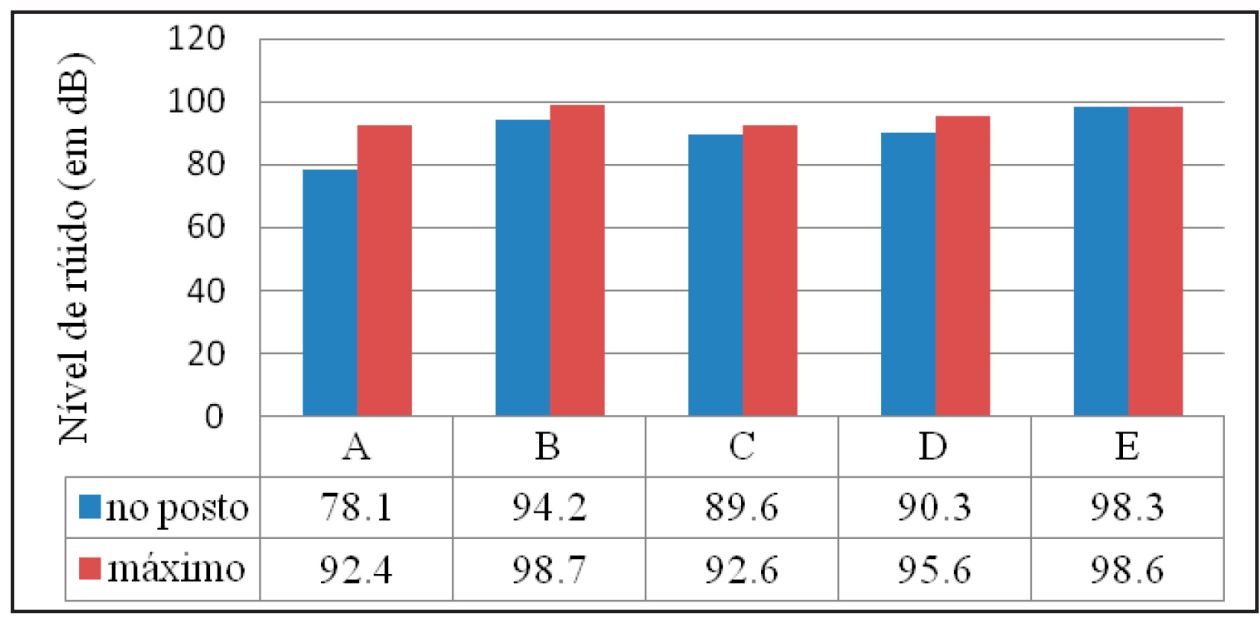

Fonte: Autores (2014)

Buscando um parâmetro de avaliação do grau de atenuação de cada máquina foi realizada a análise estatística, com utilização do teste t. A máquina E foi a única que não comprovou uma diferença entre as médias de ruído no posto de trabalho e a máxima encontrada. Considerou-se um nível de significância de 5\%. O resultado é expresso na Tabela 3.

Tabela 3 - Análise das diferenças das médias de ruído no posto de trabalho e a máxima para cada máquina

\begin{tabular}{lcccc}
\hline Máquina & $\begin{array}{c}\text { Média no } \\
\text { posto (para } \\
\mathbf{6} \text { medições) } \\
\text { (dBA) }\end{array}$ & $\begin{array}{c}\text { Média máxima } \\
\text { (para } \mathbf{6} \\
\text { medições) } \\
\text { (dBA) }\end{array}$ & Valor de p & $\begin{array}{c}\text { Análise estatística } \\
\text { (ao nível de 5\% de } \\
\text { significância) }\end{array}$ \\
\hline $\mathrm{A}$ & 78,1 & 92,4 & $6,24 \times 10^{-7}$ & comprova-se a diferença \\
$\mathrm{B}$ & 94,2 & 98,7 & $1,11 \times 10^{-4}$ & comprova-se a diferença \\
$\mathrm{C}$ & 89,6 & 92,6 & $2,91 \times 10^{-4}$ & comprova-se a diferença \\
$\mathrm{D}$ & 90,3 & 95,6 & $3,49 \times 10^{-3}$ & comprova-se a diferença \\
$\mathrm{E}$ & 98,3 & 98,7 & 0,465 & Não comprova-se a diferença \\
\hline
\end{tabular}

Fonte: Autores (2014) 


\section{CONCLUSÕES}

O programa Surfer ${ }^{\circledR} 8.0$ apresentou-se como uma eficiente ferramenta para visualização e geração de mapas de níveis de ruído. Ele possibilitou análises e comparações que não seriam possíveis sem o recurso gráfico.

Com exceção da máquina A, todas as demais exigem (segundo a NR 15) a utilização do protetor auricular no posto de trabalho para uma jornada de trabalho de 8 horas diária.

Todas as máquinas apresentaram pontos, fora do posto do operador, com níveis de ruído acima dos $85 \mathrm{~dB}(\mathrm{~A})$ preconizado pela norma.

Para todos os tratores, cujas distâncias seguras oscilaram de 3 a 6,5 metros, evidenciou-se que trabalhadores que estejam sobre a máquina (no posto de trabalho ou fora) experimentam níveis de ruído elevados que exigem a utilização de EPI. Até mesmo auxiliares em solo ou sobre implementos agrícolas podem sofrer prejuízos à audição.

No motocultivador, cuja distância segura foi de 3,8 metros, seu emprego para o transporte de pessoas na carreta, embora seja proibido em vias públicas, é prática comum na região avaliada, implica na exposição de passageiros a níveis de ruídos perigosos, similares aos experimentados pelo operador.

A motosserra apresenta-se como a máquina onde o operador está mais susceptível ao ruído, comprovado pelo teste t, e cuja distância segura foi mais expressiva: 4,7 metros. Especialmente se utilizada em frentes de trabalho há elevado risco de danos à audição de pessoas que estejam executando outras operações nas imediações da máquina e que não estejam devidamente protegidas.

A forte correlação entre o nível de ruído e a distância de segurança concorda com o senso de que quanto maior o nível de ruído de uma máquina maior a necessidade de afastamento desta. A correlação positiva forte entre o ruído e a RPM demonstra a importância do operador não exceder a faixa de rotação indicada pelo fabricante da máquina. 


\section{REFERÊNCIAS}

BIESTERVELD, A. C. et al. Using Surfer 8 to interpret light non-aqueous phase liquid monitoring data: a case study. Environ. Pract., [s.I.], v. 6, n. 4, p. 316-321, 2004.

CARVALHO, C. C. S. Avaliação ergonômica em operações do sistema produtivo de carne de frango. 2009. Tese (Doutorado em Engenharia Agrícola) - Universidade Federal de Viçosa, Viçosa-MG, 2009.

CUNHA, J. P. A. R.; DUARTE, M. A. V.; RODRIGUES, J. C. Avaliação dos níveis de vibração e ruído emitidos por um trator agrícola em preparo do solo. Pesq. Agropec. Trop., Goiânia, v. 39, n. 4, p. 348-355, out./dez. 2009.

IIDA, I. Ergonomia: Projeto e Produção. São Paulo: Edgard Blucher, 2005.

LIMA, J. S. S. et al. Avaliação de alguns fatores ergonômicos nos tratores "Feller-Buncher" e "Skidder" utilizados na colheita de madeira. R. Árvore, Viçosa, MG, v. 29, n. 2, p. 291-298, 2005.

MACHADO, C. C. Colheita florestal. 3. ed. Viçosa, MG: UFV, 2014.

NORONHA, E. H. et al. Quantificação dos níveis de ruídos num estande de tiros da PM do Distrito Federal. Humanitates, Brasília, DF, v. 1, n. 3, 2005.

OLIVEIRA, P. C. G. et al. Variabilidade espacial de propriedades químicas do solo e da produtividade de citrosna Amazônia Oriental. R. Bras. Eng. Agríc. Ambiental, [s.l.], v. 13, n. 6, p.708-715, 2009.

ORGANIZAÇÃO PARA A COOPERAÇÃO E DESENVOLVIMENTO ECONÔMICO. Code 5. Disponível em: http://www.oecd.org/tad/code/Code\%2010\%20-\%20Final.pdf. Acesso em: 27 abr. 2014.

ROQUE, M. W. et al. Correlação linear e espacial entre a resistência do solo ao penetrômetro e a produtividade do feijoeiro irrigado. R. Bras. Ci. Solo, [s.I.], v. 32, n. 5, p. 1827-1835, 2008.

SANT'ANNA, C. M. et al. Melhoria das condições de segurança no uso de motosserras. In: SIMPÓSIO BRASILEIRO SOBRE COLHEITA E TRANSPORTE FLORESTAL, 2., 1995, Salvador. Anais [...]. Viçosa: SIF/UFV, p. 173-186, 1995.

SANT'ANNA, C. M.; MALINOVSKI, J. R. Avaliação da segurança no trabalho de operadores de motosserra no corte de eucalipto em região montanhosa. Ciênc. Florest., Santa Maria, v. 9, n. 2, p. 75-84, 1999.

SCHLOSSER, J. F.; DEBIASI, H. Conforto, preocupação com o operador. Rev. Cultivar Máquinas., [s.I.], n. 1, p. 3-9, 2002.

SEGURANÇA e medicina do trabalho. 67. ed. São Paulo: Atlas, 2011.

SIMONE, M. et al. El tractor agrícola: fundamentos para su selección y uso. Mendoza: INTA, 2006.

VEIGA R. K. et al. Multitarefas. Rev. Cultivar Máquinas, [s.I.], v.12, n. 142: 6-9, 2014. 
SOFTWARE designed to display your data: developed to exceed your expectations. 2014. Disponível em: http://downloads.goldensoftware.com/guides/GSIWebBrochure.pdf. Acesso em: 10 mar. 2014.

VENTURI, J. et al. Utilização do software Surfer ${ }^{\circledR} 8.0$ para a análise de ruído em máquinas agrícolas. In: ENCONTRO NACIONAL DE ENGENHARIA DE PRODUÇÃO, 34., 2014. Anais [...]. Curitiba, PR, ENEGEP, 2014.

WICTOR, I. C., BAZZANELLA, S. L. Avaliação ergonômica do nível de ruído e as causas de acidentes de trabalho em empresas madeireiras. In: SIMPÓSIO DE EXCELÊNCIA EM GESTÃO E TECNOLOGIA-SEGET, 9., 2012. Anais [...]. Resende, RJ, 2012.

YANAGI JUNIOR, T. et al. Spatial variability of noise level in agricultural machines. Eng. Agríc., Jaboticabal, v. 32, n. 2, p. 217-225, 2012.

\section{Contribuição de Autoria}

\section{1 - Ricardo Kozoroski Veiga}

Engenheiro Mecânico, Dr., Professor

https://orcid.org/0000-0001-6589-7582•ricardo.veiga@ifc.edu.br

Contribuição: Conceituação, Curadoria de dados, Supervisão, Investigação, Metodologia, Administração do projeto, Recursos, Software, Supervisão, Validação, Visualização, Escrita - primeira redação, Escrita - revisão e edição

\section{2 - Leila Amaral Gontijo}

Desenhista Industrial, Dra., Professora

https://orcid.org/0000-0001-9705-5232•leila.gontijo@ufsc.br

Contribuição: Administração do projeto, Curadoria de dados, Escrita - primeira redação

\section{3 - Fabrício Campos Masiero}

Engenheiro Agrônomo, Dr., Professor

https://orcid.org/0000-0001-9224-3314•fabricio.masiero@ifc.edu.br

Contribuição: Metodologia, Curadoria de dados, Escrita - revisão e edição 


\section{4 - Juclei Venturi}

Engenheiro Agrônomo

https://orcid.org/0000-0001-5661-8836•jucleixd@hotmail.com

Contribuição: Conceituação, Curadoria de dados, Análise Formal, Investigação, Metodologia, Administração do projeto, Validação, Visualização, Escrita - primeira redação, Escrita - revisão e edição

\section{Como citar este artigo}

Veiga, R. K.; Gontijo, L. A.; Masiero, F. C.; Venturi, J. Análise e distribuição espacial do ruído no posto de trabalho do operador e nas proximidades de máquinas agrícolas e florestais. Ciência Florestal, Santa Maria, v. 31, n. 1, p. 43-65, 2021. DOI 10.5902/1980509816116. Disponível em: https://10.5902/1980509816116. Acesso em: xx mês abreviado 202x. 